\title{
Uptake of dissolved organic selenides by marine phytoplankton
}

\author{
Stephen B. Baines and Nicholas S. Fisher \\ Marine Sciences Research Center, State University of New York, Stony Brook, New York 11794-5000
}

Martina A. Doblin and Gregory A. Cutter

Department of Ocean, Earth and Atmospheric Sciences, Old Dominion University, Norfolk, Virginia 23529-0276

\begin{abstract}
$\mathrm{Se}$ is present in multiple oxidation states in nature, each of which has unique chemical and biological reactivities. As a consequence, the rate of Se incorporation into food webs or its role as either a limiting nutrient or a toxic substance is a function of complex biogeochemistry. In particular, little is understood about the accumulation of dissolved organic selenides by phyto- or bacterioplankton. We assessed the bioavailability of dissolved organic selenides to marine and estuarine phytoplankton by presenting various algal species with filtered lysates of the diatom, Thalassiosira pseudonana, grown on media amended with radiolabeled selenite ( $\left.{ }^{75} \mathrm{Se}[\mathrm{IV}]\right)$. Species known to accumulate selenite effectively also accumulated Se from radiolabeled cell lysates and to approximately the same extent. When exposed to a 4.5-nM solution of lysate Se, T. pseudonana, Heterocapsa triquetra (Dinophyceae), Tetraselmis levis (Prasinophyceae), Synechococcus bacillus (Cyanobacteria), and Dunaliella tertiolecta (Chlorophyceae) incorporated $42 \%-53 \%, 42 \%, 30 \%, 32 \%$, and $4 \%$ of the dissolved Se, respectively. Se cell contents of $T$. pseudonana, T. levis, and D. tertiolecta grown in media containing $4.5 \mathrm{nM}$ lysate Se were very similar to Se content of cells grown in $4.5 \mathrm{nM}$ selenite. Our results suggest that recycling of $\mathrm{Se}(-\mathrm{II})$ may be more important than previously thought. Consequently, uptake of organic selenides by phytoplankton may need to be considered in models predicting Se incorporation into aquatic food webs, given that it is a significant fraction of dissolved Se in estuarine and oceanic waters.
\end{abstract}

Se can act as a limiting nutrient for marine organisms at low concentrations or as a toxic contaminant when concentrations in organismal tissues are sufficiently elevated (Harrison et al. 1988; Lauchli 1993; Lemly 1996). The existence of multiple oxidation states of Se in natural waters complicates prediction of Se accumulation into plankton food webs, because the different forms have different biological reactivities (Wrench and Measures 1982; Cutter and Bruland 1984). Uptake of inorganic forms of dissolved Se, i.e., selenite (Se[IV]) and selenate (Se[VI]), by phytoplankton and bacteria is widely presumed to be the main pathway for Se into aquatic food webs (Luoma et al. 1992; Wang et al. 1996). Once incorporated by cells, the oxidized inorganic forms are reduced to organic selenides $(\mathrm{Se}[-\mathrm{II}]$ ) (Wrench and Campbell 1981; Bottino et al. 1984; Besser et al. 1994). These organic selenides, usually in the form of free and combined seleno-methionine and seleno-cysteine (Fisher and Reinfelder 1991), can then be released into the environment through excretion, cell lysis, or grazing activity (Cutter 1982; Bottino et al. 1984; Besser et al. 1994).

Dissolved organic selenides may be an important source of Se for phytoplankton cells, because they can account for $\sim 80 \%$ of the dissolved Se in open ocean surface waters and a significant fraction in many other environments as well (Wrench 1983; Cutter 1989; Cutter and Cutter 1995). Nev-

Acknowledgements:

We thank Robert Glaser, Emilie Novak, and Carrie Loughlin for technical assistance and two anonymous reviewers for helpful comments. This research was supported by grants from the NSF (OCE9714308) and CalFed (B103) to N. Fisher and NSF grant OCE-9707946 to G. Cutter. This is Contribution No. 1217 from the Marine Sciences Research Center. ertheless, few studies have measured the bioavailability of organic Se(-II) for phytoplankton. Because some algae assimilate dissolved organic forms of nitrogen (Paerl 1991; Peierls and Paerl 1997) and because organic Se(-II) is probably associated with organic nitrogen (Wrench and Campbell 1981), it is possible that incidental organic Se uptake by phytoplankton may occur. Alternatively, because many algae are known to have Se requirements (Price et al. 1987; Harrison et al. 1988; Doblin et al. 1999), targeted uptake of dissolved organic Se-containing compounds may occur where inorganic Se concentrations are limiting. Although organic Se in open ocean waters is thought to be relatively refractory (Cutter and Bruland 1984), in other more productive environments, organic Se may be more labile, with a large fraction being recently derived from living cells. This situation may be particularly true during the senescence period of blooms and, more continuously, in estuaries, where freshwater phytoplankton are advected into brackish water.

Some algal species can assimilate Se released by other algal cells. Gobler et al. (1997) observed that Se in unfiltered viral lysates of the marine brown tide alga Aureococcus anophagefferens could be assimilated by the diatom, Thalassiosira pseudonana. It is not clear whether the form of Se taken up was organic $\mathrm{Se}(-\mathrm{II})$ or $\mathrm{Se}(\mathrm{IV})$ produced by extracellular oxidation of the organic Se. Some freshwater algae are known to assimilate seleno-methionine (Riedel et al. 1991). No studies have unequivocally determined whether the organic Se released by decomposing phytoplankton is available to other phytoplankton, thus possibly augmenting uptake of inorganic forms of Se. Uptake of single Se-containing compounds may not reflect natural processes, because ambient pools of organic Se are complex mixtures (Cutter 1982; Cutter and Cutter 1995). Moreover, uptake of 
Se from the dissolved organic pool may vary greatly among species, as has been shown for Se(IV) (Baines and Fisher 2001). In the present article, we assessed the uptake of Se in filtered algal lysates relative to the uptake of $\mathrm{Se}(\mathrm{IV})$ for five phytoplankton species (four eucaryotic algae and one cyanobacterium) that vary widely in their ability to concentrate inorganic $\mathrm{Se}(\mathrm{IV})$.

\section{Materials and Methods}

The species used in the experiments were T. pseudonana (Bacillariophyceae), Dunaliella tertiolecta (Chlorophyceae), Heterocapsa triquetra (Dinophyceae), Synechococcus bacillus (Cyanophyceae), and Tetraselmis levis (Prasinophyceae). These species were selected because they represent a wide taxonomic range and vary greatly in their ability to take up $\mathrm{Se}(\mathrm{IV})$ (Baines and Fisher 2001). Cells were grown in sterile filtered seawater (SFSW, $0.2 \mu \mathrm{m}$ filtered water collected from $8 \mathrm{~km}$ off Southampton, NY, salinity 35) amended with $\mathrm{f} / 2$ nutrients (Guillard and Ryther 1962) at $16^{\circ} \mathrm{C}$ and with a $14: 10 \mathrm{~h}$ light: dark cycle. Light flux to cultures averaged 70 $\mu$ Ein $\mathrm{m}^{-2} \mathrm{~s}^{-1}$.

Organic ${ }^{75} \mathrm{Se}(-\mathrm{II})$ was produced by growing T. pseudonana in media amended with ${ }^{75} \mathrm{Se}-$ labeled Se(IV). Nonradioactive $\mathrm{Se}(\mathrm{IV})$ and ${ }^{75} \mathrm{Se}(\mathrm{IV})$ were added to 1 liter of medium, to achieve a final concentration of $20 \mathrm{nM}$ selenite and an activity of $15.5 \mathrm{kBq} \mathrm{L}^{-1}$. Prior experiments have indicated that cultures of $T$. pseudonana would remain Se-replete if initial $\mathrm{Se}(\mathrm{IV})$ concentrations were $>15 \mathrm{nM}$ (Baines and Fisher 2001). Exponential phase T. pseudonana cells were inoculated at an initial concentration of $1 \times 10^{4} \mathrm{ml}^{-1}$ and were allowed to grow until cell densities reached $3 \times 10^{6}$ $\mathrm{ml}^{-1}(4-5 \mathrm{~d})$. The cells were then filtered onto $1.0 \mu \mathrm{m}$ polycarbonate membranes and resuspended into $200 \mathrm{ml}$ of SFSW. The solution containing resuspended cells was subjected to three freeze-thaw cycles. During each cycle, the solution was frozen overnight at $-4^{\circ} \mathrm{C}$, allowed to melt in a flow through water bath at room temperature $\left(23^{\circ} \mathrm{C}\right)$, and then placed in the freezer immediately after the last of the ice was melted. After the last thaw, the solution was filtered through $0.2-\mu \mathrm{m}$ membrane filters and the filtrate frozen or used immediately. Solutions were kept on ice during this procedure to limit bacterial activity. If frozen, lysates were used within $1 \mathrm{~d}$ of production.

Uptake of lysate Se and Se(IV) was assayed in parallel experiments. Lysate ${ }^{75} \mathrm{Se}$ and inorganic ${ }^{75} \mathrm{Se}$ (IV) were added to $250-\mathrm{ml}$ Erlenmeyer flasks that contained $125 \mathrm{ml}$ of SFSW amended with $\mathrm{f} / 2$ nutrients to achieve a final concentration of $4.5 \mathrm{nM} \mathrm{Se}$. The first set of experiments was conducted using $H$. triquetra, T. pseudonana, and $S$. bacillus. The second set used $T$. pseudonana, D. tertiolecta, and T. levis. In the second experiment, 5-ml samples were taken at each time point and preserved with $125 \mu \mathrm{l}$ of acidic Lugol's solution for later analysis of cell number and volume by use of a Coulter Counter Multisizer II system fitted with a 70- or 100$\mu \mathrm{m}$ aperture.

Initial samples of the experimental media were taken for analysis of total and particulate radioactivity before algal inocula were added. Inocula from T. pseudonana and H. tri- quetra cultures in late exponential phase were filtered onto $1.0-\mu \mathrm{m}$ membrane filters and then resuspended into fresh SFSW. Previous experiments have indicated that cells of these species were little affected by this treatment. Cells of the other species were washed three times by first concentrating a $125-\mathrm{ml}$ aliquot of culture via centrifugation at $\approx 1,500 \mathrm{~g}$ for $10 \mathrm{~min}$, then pouring off the supernatant and bringing the solution back up to $125 \mathrm{ml}$ with SFSW. Initial cell concentrations for all species in the experiments were $\sim 100$ times less than cell concentrations at stationary phase under our culture conditions.

Total and particle-associated radioactivity were measured prior to adding cells and four to five times over the next 5 d (Fisher and Wente 1993). Initial values (before the addition of cells) were subtracted from later values to correct for adsorption of organic Se onto the filters, typically $1 \%-2 \%$ of the total dissolved Se. For the particulate measurements, 5$\mathrm{ml}$ aliquots of the experimental cultures were filtered onto $1.0-$ and $0.2-\mu \mathrm{m}$ polycarbonate membrane filters. These pore sizes were taken to represent, respectively, the incorporation of Se predominantly by algal cells and the combined uptake of Se by algae and bacteria. Filters were rinsed with $10 \mathrm{ml}$ of SFSW. Radioactivity on the filters and in aliquots of solution was assayed at $264 \mathrm{keV}$ for ${ }^{75} \mathrm{Se}$ with a $\mathrm{NaI}(\mathrm{Tl})$ gamma detector (Wallac-Pharmacia Compugamma). Counting times were adjusted to allow us to detect the uptake of $0.5 \%$ of the added Se into the $>1 \mu \mathrm{m}$ phase with an analytical error of $<5 \%$.

We also explored whether significant amounts of Se were being taken up as $\mathrm{Se}(\mathrm{IV})$ from the lysates. In these experiments, we diluted any ${ }^{75} \mathrm{Se}$ (IV) label present in the lysate with a large amount of unlabeled Se(IV) and examined the decline in radiolabel incorporation. Nonradioactive Se(IV) was added to a culture of T. pseudonana to achieve a Se(IV) concentration of $45 \mathrm{nM}$ in addition to the $4.5 \mathrm{nM}$ radiolabeled cell lysate ( $49.5 \mathrm{nM}$ total). Finally, we conducted an experiment to determine whether exposure to light could affect availability of dissolved Se released by algae. Radiolabeled lysate Se $(200 \mathrm{ml})$ was transferred into two gas permeable 1-liter American Fluoroseal Teflon UVB and UVC transparent bags (Amyot et al. 1994; Gobler et al. 1997), one of which was covered in aluminum foil to block light from the lysate. These bags were then placed in an outdoor water bath $\left(12^{\circ} \mathrm{C}\right)$ in the sunlight for $6 \mathrm{~h}(0900-1500 \mathrm{~h})$. After the exposure period, the solutions were dispensed into experimental cultures and Se uptake into 1.0 and $0.2 \mu \mathrm{m}$ fractions was assayed over a 1-week period to account for algal and bacterial uptake.

The ability of bacteria to contribute to the uptake of dissolved Se into the particulate phase was also assessed. In these experiments, SFSW was amended with $4.0 \mathrm{nM}$ of radiolabeled or nonlabeled lysate Se and inoculated with 10 $\mathrm{ml}$ of 0.6- $\mu \mathrm{m}$ filtered seawater taken from Stony Brook Harbor, NY. In nonlabeled cultures, bacterial abundance was enumerated at $1000 \times$ under epifluorescence using 4,6-diamidino-2-phenyl-indole (Porter and Feig 1980). Dissolved organic carbon (DOC) was determined with a Shimadzu TOC analyzer. Se speciation and bacterial uptake into the $>0.2$ $\mu \mathrm{m}$ fraction was assessed in the radiolabeled experiments for triplicate inoculated and uninoculated control flasks. 
Table 1. Fractionation of ${ }^{75} \mathrm{Se}$ at various stages of lysate production with use of the diatom T. pseudonana. Means and SDs are presented for four samples from a single production flask. Values for the culture are after $4-5 \mathrm{~d}$ of growth on $20 \mathrm{nM}{ }^{75} \mathrm{Se}$ (IV) and prior to filtration and resuspension of cells in SFSW. Values for three sequential freeze/thaw cycles reflect speciation after thawing. The values for the last freeze/thaw cycle reflect what was added to cultures.

\begin{tabular}{lcc}
\hline \hline $\begin{array}{c}\text { Step in lysate } \\
\text { production }\end{array}$ & $\begin{array}{c}\text { Particulate Se } \\
\text { (\% of total) }\end{array}$ & $\begin{array}{c}\text { Dissolved Se } \\
\text { (\% of total) }\end{array}$ \\
\hline Prefiltration & 60.1 & 39.9 \\
Mean & 1.2 & \\
SD & & \\
Freeze/Thaw 1 & 63.5 & 36.5 \\
Mean & 1.3 & \\
SD & & 70.2 \\
Freeze/Thaw 2 & 29.8 & \\
Mean & 0.9 & 81.1 \\
SD & & \\
Freeze/Thaw 2 & 18.9 & \\
Mean & 0.2 & \\
SD & & \\
\hline
\end{tabular}

Sigmoidal curves were fitted to the pooled time series data of Se uptake by use of a least-squares optimization criterion and a Levenberg-Marquardt iterative search algorithm in SigmaPlot 6.0 (step size, 100; tolerance, 0.0001). The maximum fraction of Se taken up was compared among phytoplankton species and between inorganic Se(IV) and lysate Se by use of $t$ tests on the basis of the estimates of maximum fraction of Se taken up.

Results

T. pseudonana took up $60 \%$ of the added Se(IV) in the lysate production cultures. Most $(81 \%)$ of this Se was released into the dissolved phase over the course of the three freeze-thaw cycles (Table 1). Growth of cells was exponential throughout the uptake experiments for all species, with the possible exception of $T$. levis, which exhibited a slight lag phase (Fig. 1). There were no discernible differences in growth rate between the cultures exposed to lysate Se and Se(IV).

All species took up ${ }^{75} \mathrm{Se}$ from lysates of $T$. pseudonana and from Se(IV) amended media (Fig. 2). Table 2 presents a comparison of the radioactivity captured on the $0.20 \mu \mathrm{m}$ (bacteria + phytoplankton) and $1-\mu \mathrm{m}$ (phytoplankton only) filters. In the Se(IV) uptake experiments, 94\%-123\% of the radioactivity caught on the $0.2-\mu \mathrm{m}$ filters was caught on the $1.0-\mu \mathrm{m}$ filters, with the exception of $D$. tertiolecta, for which only $62 \%$ of the radioactivity on the $0.2-\mu \mathrm{m}$ filters was found on the $1.0-\mu \mathrm{m}$ filters. Only for $T$. pseudonana in the first experiment and $D$. tertiolecta in the second was the difference between the radioactivity on the $1.0-$ and $0.2-\mu \mathrm{m}$ filters significant (paired two-tailed $t$ test, $H_{0}$ ratio $=1, \alpha=$ 0.05). In the lysate Se uptake experiments, 78\%-95\% of the radioactivity caught on the $0.2-\mu \mathrm{m}$ filters was caught on the $1.0-\mu \mathrm{m}$ filters, again with the exception of $D$. tertiolecta, for which only $41 \%$ of the radioactivity on the $0.2-\mu \mathrm{m}$ filters was found on the $1.0-\mu \mathrm{m}$ filters. The ratios of radioactivity on the 1.0- and $0.2-\mu \mathrm{m}$ filters were always larger in the $\mathrm{Se}(\mathrm{IV})$ treatments than in the lysate Se experiments, which indicates that a greater fraction of the Se was taken up by the $0.2-1.0-\mu \mathrm{m}$ size fraction in the lysate experiments. However, only for the two $T$. pseudonana experiments were the differences statistically significant (paired one-tailed $t$ test, $H_{0}$ ratio $\left.=1, \alpha=0.05\right)$

Initially, the fraction of radiolabel taken up was similar for both lysate Se and Se(IV) (Fig. 2). Thereafter, the species that took up $\mathrm{Se}(\mathrm{IV})$ most effectively, $H$. triquetra and $T$. pseudonana, continued to take up lysate Se but at a rate slower than that for Se(IV). Near the end of the experiment, Se uptake ceased for these species despite continued growth. For the other three species, the fractions of lysate $\mathrm{Se}$ and

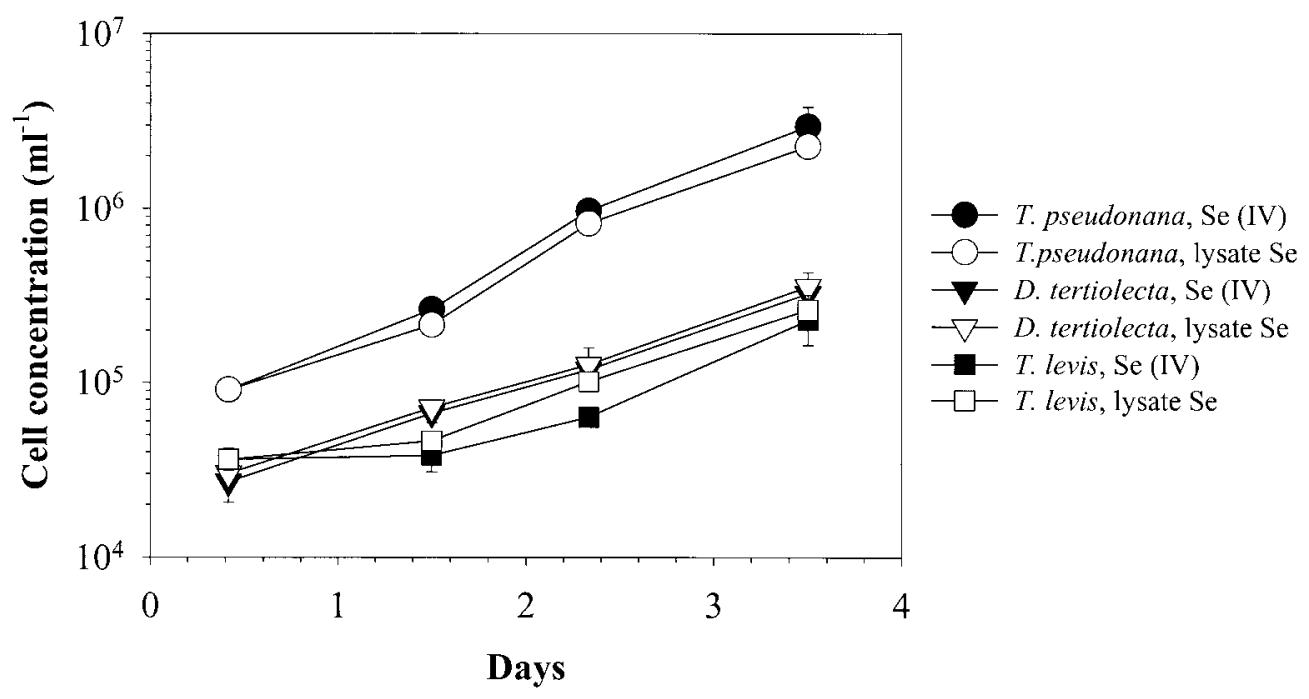

Fig. 1. Cell growth during three of the lysate Se/Se(IV) uptake experiments. Each point represents the mean of three cultures, and the error bars are $\pm 1 \mathrm{SD}$. 


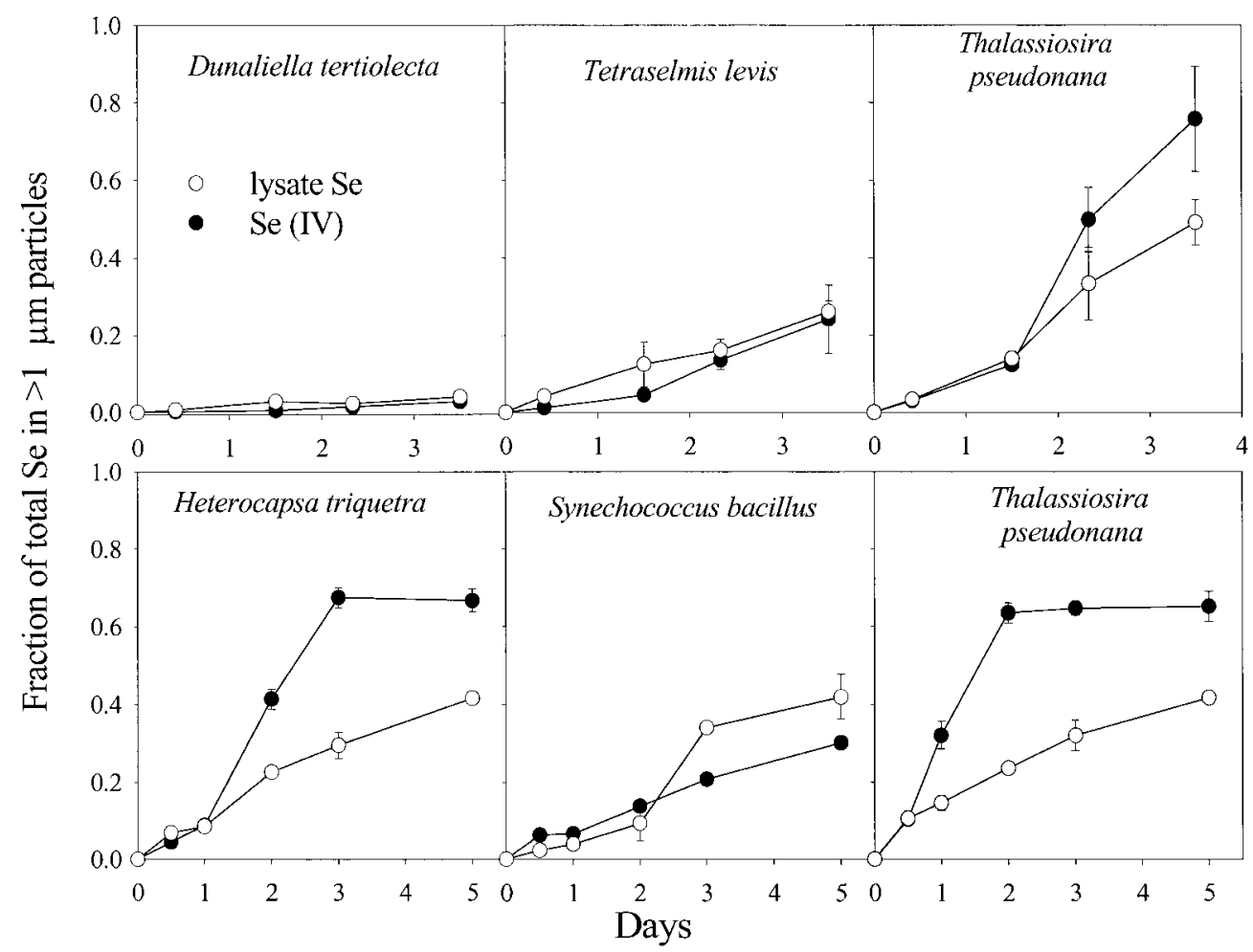

Fig. 2. The fraction of lysate taken up by particles $>1 \mu \mathrm{m}$. The upper panels are from the first set of experiments and the lower panel from the second. Dotted lines are \pm 1 SD of the means.

$\mathrm{Se}(\mathrm{IV})$ taken up were similar throughout the experiment. The mean fraction of Se taken up varied from $3 \%$ (D. tertiolecta) to $79 \%$ (T. pseudonana) for Se(IV) and $4 \%$ to $53 \%$ for lysate Se (Table 3, Fig. 3). The two values were highly correlated among species $\left(r^{2}=0.95, P=0.04\right.$, Figs. 3, 4). After $2 \mathrm{~d}$, the Se content per cell was similar between the lysate Se and $\mathrm{Se}(\mathrm{IV})$ experiments (Figs. 3, 5).

Amending lysate Se with $45 \mathrm{nM}$ selenite significantly decreased Se uptake by $T$. pseudonana cells. At $5 \mathrm{~d}$, uptake of radioactive lysate $\mathrm{Se}$ was $25 \%$ in the $\mathrm{Se}$ (IV) amended cultures, compared with $42 \%$ in the unamended cultures (Fig. $6)$. The time course of Se uptake were nearly parallel in the two treatments after the first day, which suggests similar uptake rates after an initial period of inhibition in the Se(IV)amended cultures. The availability of lysate Se to phytoplankton was not strongly affected by exposure to sunlight (Fig. 7).

Bacteria grew rapidly in the presence of lysates of T. pseudonana, reaching maximal concentrations of $6 \times 10^{6} \mathrm{ml}^{-1}$ in $6 \mathrm{~d}$ (Fig. 8). Simultaneously, DOC in the cultures dropped from $3.3 \mathrm{mg} \mathrm{L}^{-1}$ to $1.2 \mathrm{mg} \mathrm{L}^{-1}$. However, the radiotracer experiments did not reveal a significant increase in particulate Se over background during the course of the experiments, which indicates little net uptake by bacteria.

\section{Discussion}

Assessment of potential experimental artifacts-Although lysate Se and Se(IV) uptake rates varied among species, Se associated with cell lysates of $T$. pseudonana was generally taken up by the five species to a degree similar to $\operatorname{Se}(\mathrm{IV})$, a trend that is especially evident when Se contents are normalized per cell (Fig. 5). Extensive evidence indicates most intracellular $\mathrm{Se}$ in algal cells is in the form of organic Se(-II) (Bottino et al. 1984; Vandermuelen and Foda 1988; Fisher and Reinfelder 1991). Moreover, over the course of in situ decomposition experiments, Cutter (1982) found that $\sim 90 \%$ of the Se released from dead zooplankton and organic material produced by zooplankton was organic. Consequently, our results suggest that dissolved organic Se may be a significant source of Se to planktonic food webs. However, several possible experimental artifacts need to be addressed before we can support this claim fully.

Although our algal cultures were not axenic, it is highly unlikely that bacteria were responsible for the uptake we observed. We assured this by prewashing the algal inocula with sterile filtered media and ensuring that the algal cells were growing exponentially. As a result, bacterial biomass was always much less ( $>2$ orders of magnitude) than algal biomass in the cultures. Moreover, in most instances, differences in the amount of radioactivity caught on the 0.2 - and $1.0-\mu \mathrm{m}$ filters in the lysate cultures were small $(<15 \%)$; because most of the bacteria in the cultures were smaller than $1 \mu \mathrm{m}$ in size, it can be inferred that bacteria accounted for a very small fraction of the particulate $\mathrm{Se}$ in general. The exceptions to this rule were the D. tertiolecta cultures. Of the five species we assayed, cells of this species took up the least Se. Consequently, the relatively small amount of Se accumulated by bacteria apparently accounted for a larger fraction of the accumulation in the $0.2-\mu \mathrm{m}$ size fraction of 
Table 2. Ratio of radioactivity $(r)$ on $1.0-\mu \mathrm{m}$ to that on $0.2-\mu \mathrm{m}$ filters in the uptake experiments. Each ratio is the mean of four time points for experiment 1 and five time points for experiment 2. $P$ values under the $\mathrm{Se}(\mathrm{IV})$ and $\mathrm{Se}(-\mathrm{II})$ headings are for the null hypothesis that the ratio $=1$ (two-tailed $t$ test). The far right column is the $P$ value for the null hypothesis that the ratio is the same in the Se(IV) and $\mathrm{Se}(-\mathrm{II})$ experiments (paired one-tailed $t$ test).

\begin{tabular}{|c|c|c|c|c|c|c|c|c|}
\hline Species & $\begin{array}{c}\text { Experiment } \\
\text { No. }\end{array}$ & \multicolumn{3}{|c|}{$\mathrm{Se}(\mathrm{IV})$} & \multicolumn{3}{|c|}{ Lysate $\mathrm{Se}$} & $P$ value \\
\hline Heterocapsa triquetra & 1 & 0.9 & 0.1 & 0.7 & 0.8 & 0.1 & 0.1 & 0.1 \\
\hline Synechococcus bacillus & 1 & 1.1 & 0.3 & 0.8 & 0.8 & 0.1 & 0.1 & 0.2 \\
\hline T. pseudonana & 2 & 1.0 & 0.2 & 0.9 & 0.9 & 0.3 & 0.9 & 0.01 \\
\hline
\end{tabular}

these experiments. We estimate that $1 \%-2 \%$ of the added Se was accumulated by bacteria in our experiments. This estimate is in agreement with results from the bacterial uptake experiments, which showed that natural bacterial inocula did not accumulate appreciable ${ }^{75} \mathrm{Se}$ from cultures amended with radiolabeled lysate Se (Fig. 8).

The radiolabeled cell lysate Se may have included a small fraction of $\mathrm{Se}(\mathrm{IV})$. Because of the high affinity for Se(IV) exhibited by many algal species, the uptake of $\mathrm{Se}$ (IV), rather than $\mathrm{Se}(-\mathrm{II})$, might have accounted for all of the observed lysate Se uptake and generated an autocorrelation between the apparent uptake of Se(IV) and lysate Se. However, we found that diluting the ${ }^{75} \mathrm{Se}(\mathrm{IV})$ by amending lysate Se experiments with unlabeled $\mathrm{Se}(\mathrm{IV})$ at $45 \mathrm{nM}$ (10 times the experimental lysate Se concentration) caused the uptake of lysate ${ }^{75} \mathrm{Se}$ by $T$. pseudonana to decline from $42 \%$ to $25 \%$. For comparison, we can calculate the expected decline if all the radioactive ${ }^{75} \mathrm{Se}$ taken up by the phytoplankton from the lysates were in the form of $\mathrm{Se}(\mathrm{IV})$.

The amount of radiolabel taken up in an experiment, $v_{75 \mathrm{Se}}$, is equivalent to the total Se uptake, $v_{\mathrm{Se}}$, multiplied by the fraction ${ }^{75} \mathrm{Se}(\mathrm{IV}) / \mathrm{Se}(\mathrm{IV})$ and the isotopic fractionation constant, $f$. When $\mathrm{Se}(\mathrm{IV})$ is the sole source of $\mathrm{Se}, v_{\mathrm{Se}}$ depends on total $\mathrm{Se}(\mathrm{IV})$ concentration, in accordance with MichaelisMenten uptake kinetics (Baines and Fisher 2001). Consequently, $v_{75 \mathrm{Se}}=f \times\left[{ }^{75} \mathrm{Se}(\mathrm{IV})\right] \times[\mathrm{Se}(\mathrm{IV})]^{-1} \times V m \times$ $[\mathrm{Se}(\mathrm{IV})] \times(\mathrm{Km}+[\mathrm{Se}(\mathrm{IV})])^{-1}$. The ratio of $v_{75 \mathrm{Se}}$ in two

Table 3. Maximum percentage of total Se taken up during $\mathrm{Se}(\mathrm{IV})$ and lysate Se uptake experiments. Means calculated by fitting hyperbolic curves to the data. SD = standard deviation of regression coefficient for maximal uptake. All means are significantly different from $0(P<0.001)$.

\begin{tabular}{lcccccc}
\hline \hline & & \multicolumn{2}{c}{$\operatorname{Se}(\mathrm{IV})$} & & \multicolumn{2}{c}{ Lysate Se } \\
\cline { 3 - 4 } \multicolumn{1}{c}{ Species } & $\begin{array}{c}\text { Experiment } \\
\text { No. }\end{array}$ & $\begin{array}{c}\text { Mean } \\
(\%)\end{array}$ & SD & $\begin{array}{c}\text { Mean } \\
(\%)\end{array}$ & SD \\
\hline Thalassiosira pseudonana & 1 & 79 & 5 & 53 & 5 \\
Heterocapsa triquetra & 1 & 69 & 1 & 42 & 2 \\
Synechococcus bacillus & 1 & 42 & 2 & 32 & 2 \\
T. pseudonana & 2 & 65 & 1 & 42 & 3 \\
Dunaliella tertiolecta & 2 & 3 & 1 & 4 & 1 \\
Tetraselmis levis & 2 & 27 & 6 & 30 & 6 \\
\hline
\end{tabular}

experiments with different amounts of $\mathrm{Se}(\mathrm{IV})$ but the same amount of ${ }^{75} \mathrm{Se}(\mathrm{IV})$ reduces to $v_{75 \mathrm{Se} 1} / v_{75 \mathrm{Se} 2}=\left(K_{m}+[\mathrm{Se}(\mathrm{IV})]_{2}\right)$ $\times\left(K_{m}+[\mathrm{Se}(\mathrm{IV})]_{1}\right)^{-1}$. This equation accounts for both the decrease in ${ }^{75} \mathrm{Se}(\mathrm{IV})$ uptake due to dilution of radiolabel with unlabeled $\mathrm{Se}(\mathrm{IV})$ and the increase in total Se uptake due to the increase in total $\mathrm{Se}(\mathrm{IV})$ concentration. The $K_{m}$ for $T$. pseudonana is $0.2 \mathrm{nM}$ for Se(IV) (Baines and Fisher 2001), and our estimates of Se(IV) concentrations are 0.8 and 45.8 $\mathrm{nM}$ for the unamended (i.e., ${ }^{75} \mathrm{Se}$ only) and amended $\left({ }^{75} \mathrm{Se}\right.$ $+\mathrm{Se}[\mathrm{IV}])$ experiments, respectively. Thus, if Se(IV) were the sole source of Se to the phytoplankton in the lysate uptake experiments, the expected ratio of ${ }^{75} \mathrm{Se}$ uptake in the amended and unamended experiments would be $46: 1$. This expected ratio is 27 times larger than observed, which indicates that most of the lysate Se uptake probably reflects incorporation of $\mathrm{Se}(-\mathrm{II})$ or, possibly, $\mathrm{Se}(\mathrm{VI})$.

It is very unlikely, however, that uptake of $\mathrm{Se}(\mathrm{VI})$ in the lysate Se could have accounted for the observed amount of Se incorporation. Studies of Se released by dead or decomposing phytoplankton indicate that at most $9 \%$ of released $\mathrm{Se}$ is in the form of inorganic Se, mostly Se(IV) (Cutter 1982). Moreover, transformation rates of Se(IV) to $\mathrm{Se}(\mathrm{VI})$ are very slow, even though $\mathrm{Se}(\mathrm{VI})$ is the thermodynamically

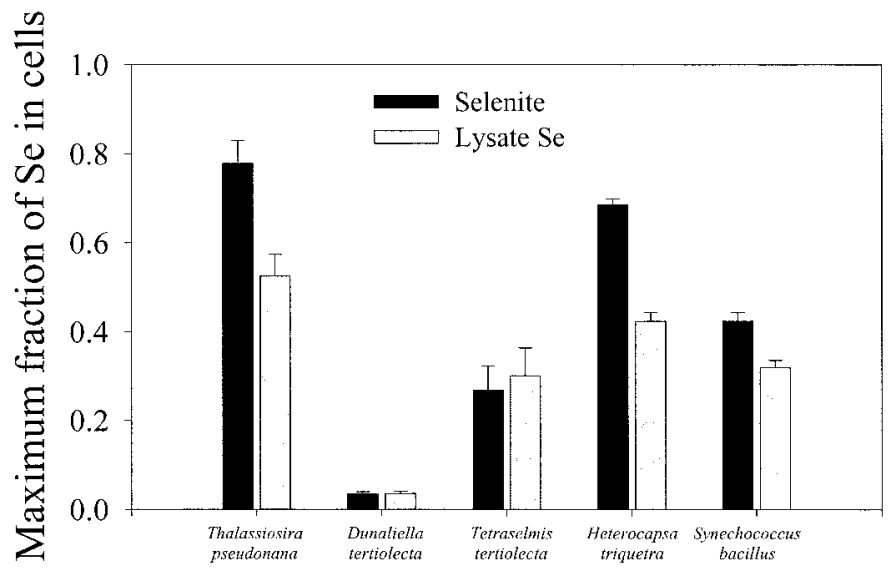

Fig. 3. Maximum fraction of Se taken up from solutions containing $4.5 \mathrm{nM}$ of Se(IV) or lysate Se for five species. Means are determined by regression of time series of Se uptake (see text). Error bars are \pm 1 SD of regression coefficient. 


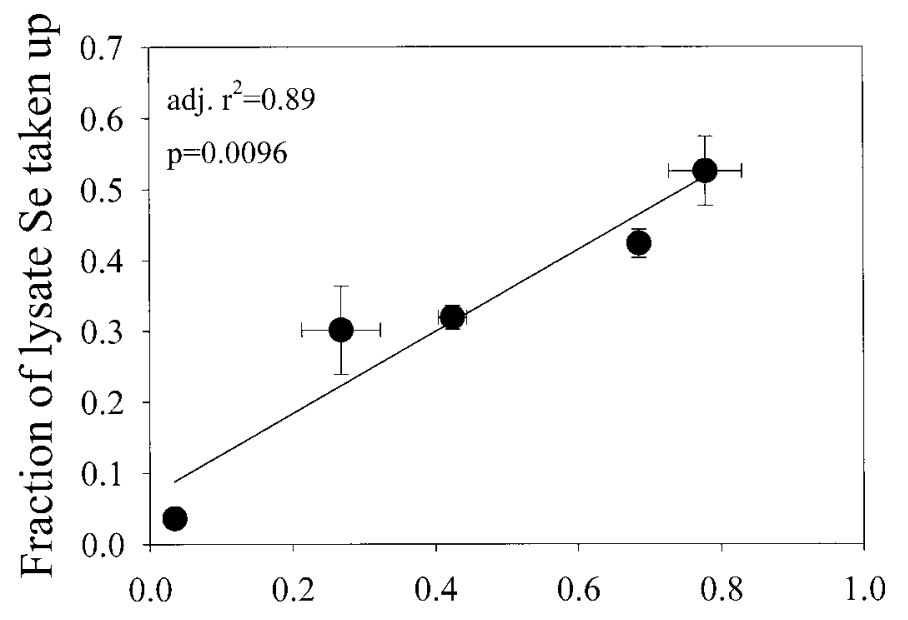

\section{Fraction of Se(IV) taken up}

Fig. 4. Correlations between maximal fraction of lysate and inorganic Se taken up among the five species used in the experiments. Error bars are $\pm 1 \mathrm{SD}$ around regression estimates (see text).

preferred form of Se under oxic conditions (Cutter and Bruland 1984). Thus, we do not expect that Se(VI) could have been produced in large quantities in the lysate addition experiments. Even if it were produced, the uptake of $\mathrm{Se}(\mathrm{VI})$ would have been relatively slow. Se(IV) is preferentially taken up by marine algal cells over Se(VI) (Vandermuelen and Foda 1988; Hu et al. 1997).

Cellular Se regulation and estimation of total Se uptakeThe decline in radiolabeled lysate Se uptake by $T$. pseudonana in the presence of $45 \mathrm{nM}$ unlabeled Se(IV) may indicate that $\sim 40 \%$ of the Se uptake from the cell lysate was actually due to uptake of Se(IV) produced by mineralization of the organic $\mathrm{Se}(-\mathrm{II})$. If this were true, the Se uptake in the experiments amended with unlabeled $45 \mathrm{nM} \mathrm{Se}(\mathrm{IV})$ may better reflect organic Se uptake than does the uptake measured in the experiments containing only lysates. However, the lower uptake of ${ }^{75} \mathrm{Se}$ in the experiments amended with unlabeled $\mathrm{Se}(\mathrm{IV})$ may also reflect cellular regulation of internal Se stores-i.e., the cells may have decreased their uptake of organic Se in response to higher $\mathrm{Se}(\mathrm{IV})$ uptake rates so as to maintain some preferred cellular Se concentration. If this were true, the uptake of ${ }^{75} \mathrm{Se}$ in the experiments amended only with lysate would provide a better estimate of maximal organic Se uptake, but the prediction of algal Se uptake at subsaturating ambient dissolved Se concentrations would be more complicated, given that interactions between $\mathrm{Se}$ (IV) and $\mathrm{Se}(-\mathrm{II})$ would have to be considered.

Such physiological regulation of Se cellular concentrations in $T$. pseudonana and other algae probably occurs. First, many diatoms and dinoflagellates are known to have growth requirements for Se (Harrison et al. 1988; Danbara and Shiraiwa 1999; Doblin et al. 1999), whereas they also exhibit toxic responses to high Se concentrations (Wong and Oliveira 1991). Furthermore, cellular concentrations of Se are dynamically maintained. In short-term experiments relating $\mathrm{Se}(\mathrm{IV})$ uptake to ambient concentration, T. pseudon-

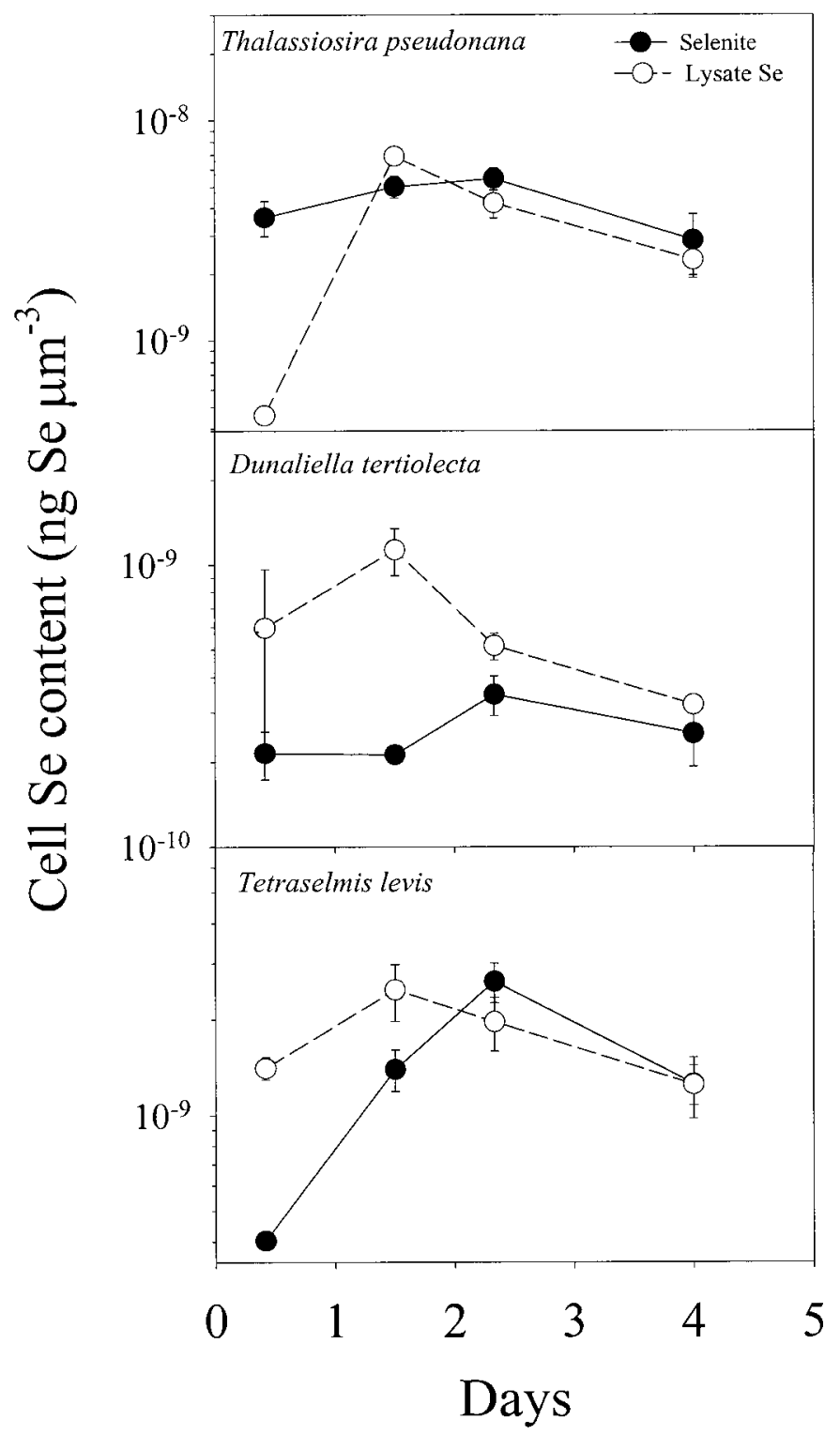

Fig. 5. Se per algal cell for the second experiment. Each point is the mean of three cultures. Error bars are \pm 1 SD.

ana cells attain steady-state Se cell concentrations after only $8 \mathrm{~h}$, which indicates that the Se pool is dynamic and probably consists of primary metabolites or enzymes with quick turnover times (Fisher and Reinfelder 1991). This observation is consistent with the observation that most of the Se in $T$. pseudonana cells is present as seleno-amino acids (Fisher and Reinfelder 1991).

Ecological consequences of Se uptake-Typically, natural bacteria exhibit much higher affinity for major dissolved organic substances than do algae (Wright and Hobbie 1966). Consequently, the importance of dissolved organic matter to the energy and carbon balance of phytoplankton cells is likely to be minimal except where external dissolved organic concentrations have not been depleted by bacterial activity, such as immediately after an algal bloom or in waters in 


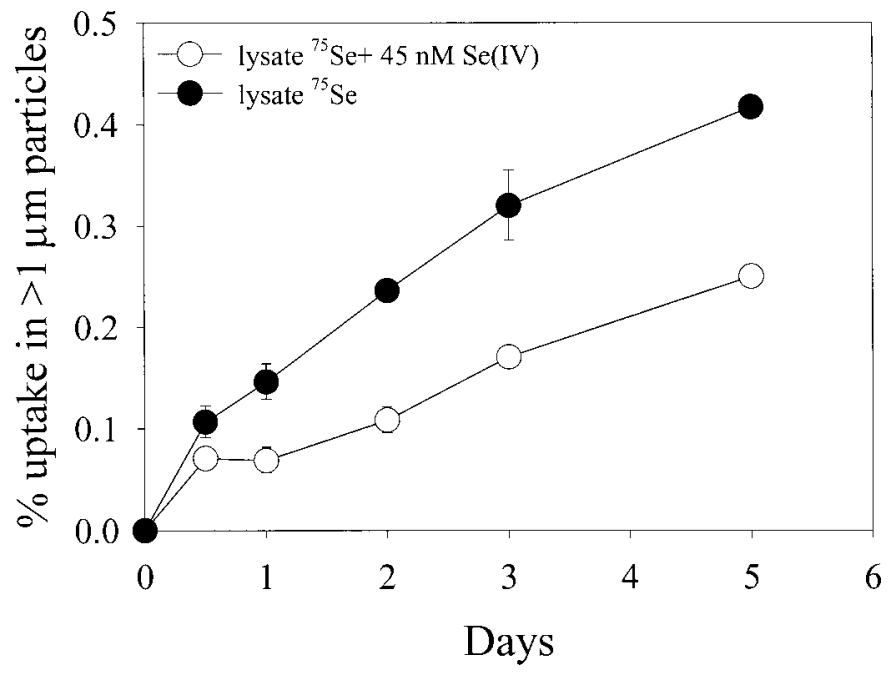

Fig. 6. Uptake of ${ }^{75} \mathrm{Se}$ from cell lysates by T. pseudonana in the presence and absence of unlabeled $45 \mathrm{nM} \mathrm{Se}(\mathrm{IV})$. Each point represents the mean of three flasks $\pm 1 \mathrm{SD}$.

which there are pulses of allochthonous organic material. However, phytoplankton may be very effective at taking up specific substances that can be used to meet needs other than $\mathrm{C}$ and energy. For example, many species of algae show high-affinity uptake for organic compounds, particularly vitamins, which they require and cannot synthesize (Droop 1968). Organic matter that contains critical limiting elements may also be targeted for direct uptake. For example, dissolved organic nitrogen (DON) and phosphorus uptake by many phytoplankton species has been observed in both marine and freshwater species (e.g., Paerl 1991; Bronk and Glibert 1993; Peierls and Paerl 1997). Uptake of DON is particularly relevant to dissolved organic Se uptake, because much organic Se is probably associated with nitrogenous organic compounds that contain seleno-methionine or seleno-cysteine (Wrench and Campbell 1981; Bottino et al. 1984; Fisher and Reinfelder 1991).

Although none of our experimental cultures were limited by $\mathrm{Se}$, the accumulation of organic $\mathrm{Se}(-\mathrm{II})$ observed here suggests a possible way for phytoplankton in situ to meet their Se requirements when dissolved inorganic Se concentrations are insufficient. Several algal species are known to have growth requirements for Se (Price et al. 1987; Harrison et al. 1988), and the Se-containing antioxidant enzyme glutathione peroxidase is produced in some phytoplankton (Price and Harrison 1988). Depletion of inorganic Se is especially likely during bloom periods, because algae which accumulate $\mathrm{Se}(\mathrm{IV})$ do so efficiently (Wrench and Measures 1982; Baines and Fisher 2001). Utilization of organic Se may allow these species to persist longer and obtain a higher standing biomass than would otherwise be possible. Uptake of organic Se may also be important in the open ocean, where $\mathrm{Se}(\mathrm{IV})$ and $\mathrm{Se}(\mathrm{VI})$ concentrations can be very low relative to organic $\mathrm{Se}(-\mathrm{II})$ (Cutter and Bruland 1984; Cutter and Cutter 1995).

Ambient organic $\mathrm{Se}(-\mathrm{II})$ may be less available to phytoplankton than the lysate produced in this study. Cutter and Bruland (1984) and Cutter and Cutter (1998) have shown

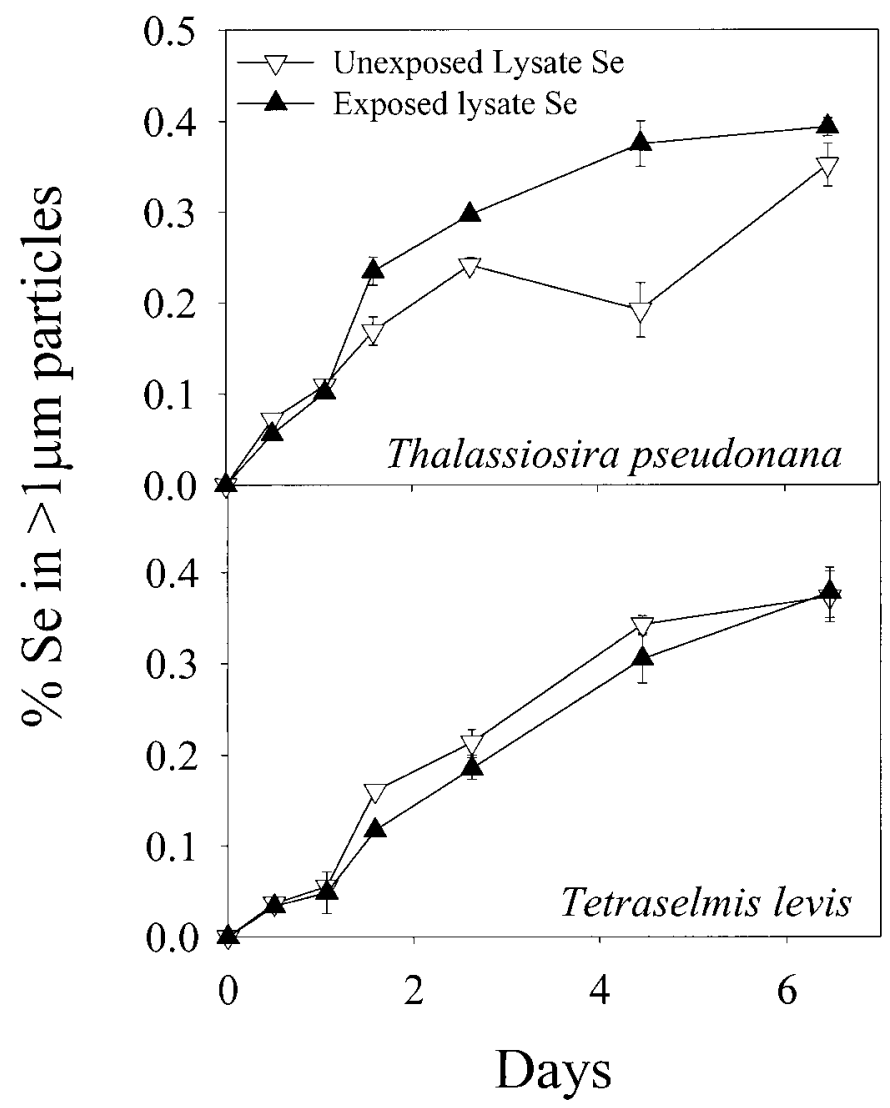

Fig. 7. Incorporation of radiolabeled lysate Se that was either kept in the dark or exposed to $6 \mathrm{~h}$ of sunlight around noon (0900-1500 h). Symbols represent means of three cultures; error bars are \pm 1 SD.

that organic Se probably has a 10 -yr residence time in the ocean. They conclude that almost all of this pool is refractory. Nonetheless, organic Se in the open ocean is probably less refractory than the bulk of DOC; the turnover time is significantly longer for bulk DOC than for organic Se(-II), and DOC persists in abundance in deep waters, whereas organic $\mathrm{Se}(-\mathrm{II})$ is largely depleted below $1000 \mathrm{~m}$ (Cutter and

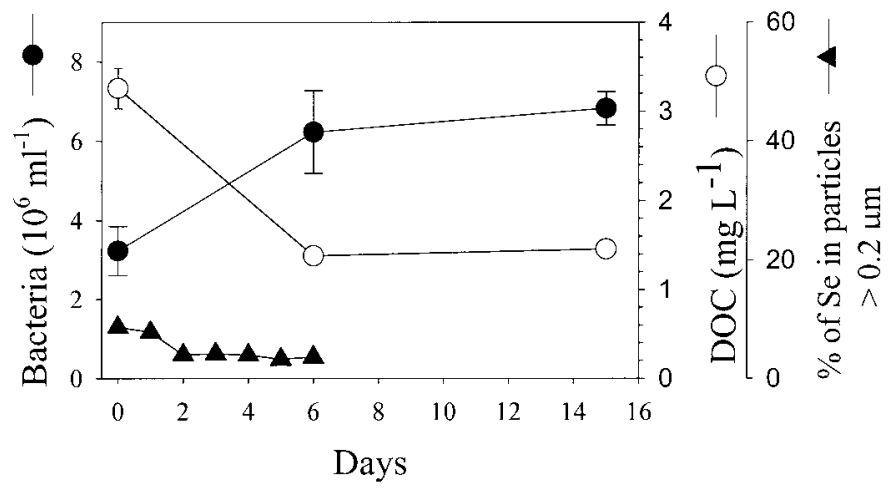

Fig. 8. Growth of bacteria and decline in DOC over $16 \mathrm{~d}$ for media containing cell lysates and inoculated with bacteria from Stony Brook Harbor. Each point represents the mean of three flasks. Error bars are \pm 1 SD. 
Cutter 1995). Although phytoplankton are not likely to take up such material in quantities large enough to affect shortterm biogeochemical processes in the open ocean, in some cases where both inorganic $\mathrm{Se}(\mathrm{IV})$ and $\mathrm{Se}(\mathrm{VI})$ are depleted, even low uptake of organic Se could allow some species to survive Se limitation more effectively.

The lysate Se in our experiments is probably more representative of organic Se released by decaying phytoplankton at the end of phytoplankton blooms or more chronically in estuaries at the turbidity maximum where freshwater phytoplankton advected into the system lyse because of osmotic stress. Where algae are abundant upstream, this continuous input of Se to the estuary may be an important source of Se to the resident food web. The difference between typical and potentially toxic tissue concentrations of $\mathrm{Se}$ is unusually small, sometimes differing by as little as a factor of four (Coughlan and Velte 1989). We have found that, in some estuaries, ambient concentrations of Se(IV) are high enough to result in algal cellular Se concentrations that could lead to toxic responses in consumers (Baines and Fisher 2001). Any augmentation of Se uptake by these cells via uptake of organic $\mathrm{Se}(-\mathrm{II})$ could therefore be problematic, particularly in localities where labile organic $\mathrm{Se}(-\mathrm{II})$ is continually being supplied by lysing cells (i.e., at river mouths and turbidity maxima).

Conclusions-Our results show that Se released by the algal cell lysis can be accumulated by marine phytoplankton to a degree roughly comparable to Se(IV). Because intracellular Se is usually present exclusively in the form of organic $\mathrm{Se}(-\mathrm{II})$, we presume that the $\mathrm{Se}$ in the lysates was organic in nature and that Se taken up from the lysates was therefore also primarily organic $\mathrm{Se}(-\mathrm{II})$. Such uptake has been observed for seleno-methionine in freshwater algae (albeit at elevated concentrations; Riedel et al. 1991) and for $\mathrm{Se}$ in viral lysates of the brown tide alga $A$. anophagefferens (Gobler et al. 1997). However, to our knowledge, the present study is the first to document that the complex of dissolved organic Se molecules released from algal cells can be taken up by diverse phytoplankton species at rates near those observed for selenite. Future work needs to address the nature of the organic $\mathrm{Se}(-\mathrm{II})$ being assimilated, the relationship between ambient concentrations of organic $\mathrm{Se}(-\mathrm{II})$ and accumulation by algae, and the potential for interactions between the various forms of Se.

\section{References}

Amyot, M., G. Nierle, D. R. S. Lean, And D. J. McQueEn. 1994. Sunlight induced formation of dissolved gaseous mercury in lake waters. Environ. Sci. Technol. 28: 2366-2371.

BAINES, S. B., AND N. S. FISHER. 2001. Interspecific differences in the bioconcentration of selenite by phytoplankton and their ecological implications. Mar. Ecol. Prog. Ser. 213:1-12.

Besser, J. M., J. N. Huckins, and R. C. Clark. 1994. Separation of selenium species released from Se-exposed algae. Chemosphere 29: 771-780.

Bottino, N. R., C. H. Banks, K. J. Irgolic, P. Micks, A. E. Wheeler, AND R. A. Zingaro. 1984. Selenium containing amino-acids and proteins in marine-algae. Phytochemistry 23: 2445-2452.
Bronk, D. A., AND P. M. Glibert. 1993. Application of a N-15 tracer method to the study of dissolved organic nitrogen uptake during spring and summer in Chesapeake Bay. Mar. Biol. 115: 501-508.

Coughlan, D. J., And J. S. Velte. 1989. Dietary toxicity of selenium-contaminated red shiners to striped bass. Trans. Am. Fish. Soc. 118: 400-408.

Cutter, G. A. 1982. Selenium in reducing waters. Science 217: 829-831.

. 1989. The estuarine behavior of selenium in San Francisco Bay. Estuar. Coast. Shelf Sci. 28: 13-34.

— of selenium-a re-evaluation. Limnol. Oceanogr. 29: 11791192 .

, AND L. S. CUTTER. 1995. Behavior of dissolved antimony, arsenic, and selenium in the Atlantic Ocean. Mar. Chem. 49: 295-306.

, AND 1 1998. Metalloids in the high latitude north Atlantic Ocean: Sources and internal cycling. Mar. Chem. 61: $25-36$.

DANBARA, A., AND Y. Shiraiwa. 1999. The requirement of selenium for the growth of marine coccolithophorids, Emiliania huxleyi, Gephyrocapsa oceanica and Helladosphaera sp. (Prymnesiophyceae). Plant Cell Physiol. 40: 762-766.

Doblin, M. A., S. I. Blackburn, AND G. M. HallegraefF. 1999. Comparative study of selenium requirements of three phytoplankton species: Gymnodinium catenatum, Alexandrium minutum (Dinophyta) and Chaetoceros cf. tenuissimus (Bacillariophyta). J. Plankton Res. 21: 1153-1169.

Droop, M. R. 1968. Vitamin $B_{12}$ and marine ecology, IV. The kinetics of uptake, growth and inhibition in Monochrysis lutheri. J. Mar. Biol. Assoc. U K 48: 689-733.

Fisher, N. S., AND J. R. REINFELDER. 1991. Assimilation of selenium in the marine copepod Acartia tonsa studied with a radiotracer ratio method. Mar. Ecol. Prog. Ser. 70: 157-164.

, AND M. WENTE. 1993. The release of trace elements by dying marine phytoplankton. Deep-Sea Res. 40: 671-694.

Gobler, C. J., D. A. Hutchins, N. S. Fisher, E. M. Cosper, AND S. A. SAÑUDO-WILHELMY. 1997. Release and bioavailability of $\mathrm{C}, \mathrm{N}, \mathrm{P}, \mathrm{Se}$, and Fe following viral lysis of a marine chrysophyte. Limnol. Oceanogr. 42: 1492-1504.

Guillard, R. R. L., AND J. H. Ryther. 1962. Studies of marine planktonic diatoms 1. Cyclotella nana Hustedt, and Detonula confervacea (Cleve) Gran. Can J. Microbiol. 8: 229-239.

Harrison, P. J., P. W. Yu, P. A. Thompson, N. M. Price, and D. J. PhILliPs. 1988. Survey of selenium requirements in marine phytoplankton. Mar. Ecol. Prog. Ser. 47: 89-96.

Hu, M. H., Y. P. YanG, J. M. Martin, K. Yin, and P. J. Harrison. 1997. Preferential uptake of $\mathrm{Se}(\mathrm{IV})$ over $\mathrm{Se}(\mathrm{VI})$ and the production of dissolved organic Se by marine phytoplankton. Mar. Environ. Res. 44: 225-231.

LAUCHLI, A. 1993. Selenium in plants-uptake, functions, and environmental toxicity. Bot. Acta 106: 455-468.

LEMLY, A. D. 1996. Assessing the toxic threat of selenium to fish and aquatic birds. Environ. Monit. Assess. 43: 19-35.

Luoma, S. N., C. Johns, N. S. Fisher, N. A. Steinberg, R. S. OREMland, AND J. R. ReInFELDER. 1992. Determination of selenium bioavailability to a benthic bivalve from particulate and solute pathways. Environ. Sci. Technol. 26: 485-491.

PAERL, H. W. 1991. Ecophysiological and trophic implications of light-stimulated amino-acid utilization in marine picoplankton. Appl. Environ. Microbiol. 57: 473-479.

Peierls, B. L., AND H. W. PAerl. 1997. Bioavailability of atmospheric organic nitrogen deposition to coastal phytoplankton. Limnol. Oceanogr. 42: 1819-1823.

Price, N. M., ANd P. J. Harrison. 1988. Specific selenium-con- 
taining macromolecules in the marine diatom Thalassiosira pseudonana. Plant Physiol. 86: 192-199.

, P. A. Thompson, and P. J. Harrison. 1987. Seleniuman essential element for growth of the coastal marine diatom Thalassiosira pseudonana (Bacillariophyceae). J. Phycol. 23: $1-9$.

Porter, K. G., AND Y. S. FeIG. 1980. The use of DAPI for identifying and counting aquatic microflora. Limnol. Oceanogr. 25: 943-948.

Riedel, G. F., D. P. Ferrier, AND J. G. SANDERs. 1991. Uptake of selenium by fresh-water phytoplankton. Water Air Soil Pollut. 57/58: $23-30$.

VANDERMEulen, J. H., AND A. FodA. 1988. Cycling of selenite and selenate in marine-phytoplankton. Mar. Biol. 98: 115-123.

WANG, W.-X., N. S. Fisher, AND S. N. LuOMA. 1996. Kinetic determinations of trace element bioaccumulation in the mussel Mytilus edulis. Mar. Ecol. Prog. Ser. 140: 91-113.
Wong, D., AND L. OliveIRA. 1991. Effects of selenite and selenate on the growth and motility of 7 species of marine microalgae. Can. J. Fish. Aquat. Sci. 48: 1193-1200.

WRENCH, J. J. 1983. Organic selenium in seawater-levels, origins and chemical forms. Mar. Chem. 12: 237.

$\longrightarrow$, AND N. C. CAMPBELl. 1981. Protein-bound selenium in some marine organisms. Chemosphere 10: 1155-1161.

, AND C. I. Measures. 1982. Temporal variations in dissolved selenium in a coastal ecosystem. Nature 299: 431-433.

Wright, R. T., AND J. E. HobBIE. 1966. Use of glucose and acetate by bacteria and algae in aquatic ecosystems. Ecology 47: 447463.

Received: 23 April 2001

Accepted: 23 July 2001

Amended: 6 August 2001 